\title{
Error Correction in Latent Inhibition and its Disruption by Opioid Receptor Blockade with Naloxone
}

\author{
Hiu T Leung*,', A S Killcross' and R Frederick Westbrook' \\ 'School of Psychology, University of New South Wales, Sydney, NSW, Australia
}

\begin{abstract}
Latent inhibition refers to the retardation in the development of conditioned responding when a pre-exposed stimulus is used to signal an unconditioned stimulus. This effect is described by error-correction models as an attentional deficit and is commonly used as an animal model of schizophrenia. A series of experiments studied the role of error-correction mechanism in latent inhibition and its interaction with the endogenous opioid system. Systemic administration of the competitive opioid receptor antagonist naloxone before rats were pre-exposed to a target stimulus prevented latent inhibition of its subsequent fear conditioning; it was without effect on a non-preexposed stimulus and did not produce state-dependent learning (Experiments I $\mathrm{a}$ and $\mathrm{I} b$ ). Naloxone did not reverse the latent inhibitory effect already accrued to a pre-exposed target. However, it did prevent the enhancement of latent inhibition by a long retention interval interpolated between its initial exposure and re-exposure (Experiment 2) or by a novel stimulus compounded with the pre-exposed target during re-exposure (Experiment 3). These results provide evidence that attentional loss in latent inhibition is instructed by an opioid-mediated error signal which diminishes with repeated stimulus exposures but recovers with the passage of time or reintroduction of novelty.

Neuropsychopharmacology (20I3) 38, 2439-2445; doi: I 0. I 038/npp.20 13.I44; published online 26 June 2013
\end{abstract}

Keywords: latent inhibition; attention; prediction error; naloxone; endogenous opioids

\section{INTRODUCTION}

A stimulus repeatedly presented in the absence of other scheduled events is slower to develop conditioned responding when paired with an unconditioned stimulus (US) than a non-pre-exposed conditioned stimulus (CS). This effect, termed latent inhibition (Lubow and Moore, 1959), is observed across various sensory modalities, in both aversive and appetitive conditioning procedures, and in subjects from a range of species including people. A notable exception is the absence of latent inhibition in acute schizophrenics, especially those afflicted with positive symptoms, and its presence after treatment with antipsychotic medication (eg, Baruch et al, 1988; Gray et al, 1995; Vaitl et al, 2002). Pre-exposure not only impairs excitatory conditioning but also inhibitory conditioning when the preexposed CS signals the absence of an expected US (Reiss and Wagner, 1972). The impairment of both conditioned excitation and inhibition demonstrates that latent inhibition is due to a loss of attention to the CS.

This loss of attention is commonly attributed to subjects learning something about the significance of the preexposed stimulus in relation to the outcome (eg, Lubow

\footnotetext{
*Correspondence: Dr HT Leung, School of Psychology, University of New South Wales, Sydney NSW 2052, Australia, Tel: +6I 29385 244I, Fax: +6I 29385 364I, E-mail: h.leung@unsw.edu.au Received 20 February 2013; revised 12 May 2013; accepted 4 June 2013; accepted article preview online 10 June 2013
}

et al, 1981; Mackintosh, 1975; Pearce and Hall, 1980). Recently, Hall and Rodriguez (2010) proposed that this attentional loss occurs as a result of an inhibitory or 'stimulus-no event' association being formed during preexposure, whose rule of establishment is governed by the same error-correction mechanism that regulates conditioning and extinction. It holds that presentation of a novel stimulus evokes an innate expectation that some event will occur. The discrepancy or so-called prediction error between this expectation (some event) and what actually occurs (nothing) produces an inhibitory association which opposes the original expectation. As the predictive value of the stimulus is brought in line with the actual outcome (nothing), attention to the stimulus is withdrawn, and no further inhibitory learning occurs.

An implication of this view is that manipulations that strengthen the inhibitory association formed during preexposure should enhance latent inhibition. One such manipulation is the passage of time between nonreinforced exposures, which has been suggested to promote further inhibitory learning by restoring prediction error when an already exposed stimulus is given additional exposures (Leung and Westbrook, 2008). Consistent with this suggestion, in latent inhibition, rats given an initial bout of preexposure to a stimulus and then given additional exposures after a passage of time showed more latent inhibition than a stimulus given equivalent but successive exposures (Holtzman et al, 2010). A second manipulation that enhances latent inhibition compounds an already pre-exposed target 
stimulus with a novel stimulus across re-exposure. The presence of the novel stimulus in the compound should again evoke an event expectation; in absence of an event, the prediction error generated by the compound causes the target stimulus to acquire a stronger inhibitory association and undergo a greater loss of attention than a stimulus pre-exposed throughout in isolation (Leung et al, 2011, 2013).

The aim of these experiments is to determine the neural mechanism that mediates error correction in latent inhibition. In Pavlovian fear conditioning, it is hypothesized that the error signal that regulates associative formation is instantiated through the endogenous opioid system (Fanselow, 1998; McNally, 2009). When an expected US is absent, that is, when prediction error is negative, systemic administration of the competitive opioid receptor antagonist naloxone impairs fear extinction (McNally and Westbrook, 2003) and the overexpectation effect (McNally et al, 2004). There is evidence that novel stimuli can activate the release of endogenous opioids (eg, Cador et al, 2002; Izquierdo et al, 1984). If such opioid response encodes the negative error signal that generates the inhibitory association during CS pre-exposure, then blockade of opioid receptors by naloxone should prevent the formation of such association and the resulting loss of attention that mediates latent inhibition. Further, if the passage of time between exposures (Holtzman et al, 2010) and compound presentations with a novel stimulus (Leung et al, 2011; 2013) restores an opioid-mediated error signal which strengthens an established inhibitory association and promote further attentional loss, then naloxone should block the resulting enhancement of latent inhibition.

These experiments used a fear conditioning procedure with rats to study the effects of naloxone on latent inhibition. Experiments $1 \mathrm{a}$ and $1 \mathrm{~b}$ aimed to demonstrate that systemic administration of naloxone before CS pre-exposure impairs the basic latent inhibition effect. Subsequent experiments examined whether the passage of time between exposures (Experiment 2) or compound presentations with a novel stimulus (Experiment 3) enhances latent inhibition, and whether such enhancement is blocked by naloxone.

\section{MATERIALS AND METHODS}

\section{General Methods}

Subjects. The subjects were 119 naive adult male Wistar rats (Rattus norvegicus, 300-450 g) obtained from Animal Resources Centre (Perth, WA, Australia). They were housed in groups of eight in plastic boxes $(67 \mathrm{~cm}$ length $\times 40 \mathrm{~cm}$ width $\times 22 \mathrm{~cm}$ height) with continuous access to food and water. They were kept in an air-conditioned colony room maintained on a 12-h light-dark cycle (lights on at 0700 hours). All procedures were carried out in the light cycle. Each rat was handled 2-3 min each day for 3 days before the experiment. The procedures were approved by the University's Animal Ethics Committee.

Apparatus and stimuli. The apparatus and stimuli were those described previously (Leung et al, 2011, 2013). Briefly, a set of four chambers $(30 \mathrm{~cm}$ height $\times 27 \mathrm{~cm}$ length $\times 30 \mathrm{~cm}$ width) was used. The CSs were a $30-\mathrm{s}$ tone $(1 \mathrm{kHz}, 70 \mathrm{db})$, clicker $(6 \mathrm{~Hz}, 65 \mathrm{db})$, steady light $(\sim 57 \mathrm{~lx})$, or flashing light (3/s). All CSs were presented after a 2-min stimulus-free period with an average intertrial interval of $60 \mathrm{~s}$, ranging from 30 to $90 \mathrm{~s}$, unless otherwise specified. A custom-built constant-current shock generator delivered the shock US $(0.8 \mathrm{~mA}, 0.5 \mathrm{~s})$ through the chamber grid floors. The behavior of each rat was captured by infrared cameras and recorded onto DVDs. All experimental events were controlled by the LabView software (National Instruments, Austin, TX).

Drugs. Naloxone hydrochloride (N7758; Sigma-Aldrich, St Louis, MO) was dissolved in $0.9 \%$ (w/v) saline and administered at a dosage of $2.5 \mathrm{mg} / \mathrm{kg}$. All injections of saline or naloxone solutions were given subcutaneously into the dorsal neck region at $1.0 \mathrm{ml} / \mathrm{kg} 5 \mathrm{~min}$ before behavioral procedures.

\section{Experiments 1a and 1b: Effects of Naloxone on Latent Inhibition}

Design. Experiment 1 a used a $(2) \times 2$ design to examine whether stimulus-alone exposures activate the endogenous opioids system, which is critical for subsequent latent inhibition. Rats were pre-exposed to a CS (A) under either saline (Group Saline) or naloxone (Group Naloxone). All rats were then conditioned to the pre-exposed CSA and a control CSB and tested with each drug-free. If latent inhibition is mediated by opioids, then naloxone should block the latent inhibition effect in CSA over and above any nonspecific effects that may be evident in CSB. Experiment $1 \mathrm{~b}$ used the same design but tested all rats under naloxone to examine whether any such effect of naloxone at pre-exposure was due to state dependency (Table 1).

Procedure. Rats were allocated randomly to two groups: Group Saline $(n=8)$ and Group Naloxone $(n=8)$. CSs were a tone and a flashing light and were counterbalanced in each group. On Days 1 and 2, rats received twice-daily 30-min exposures to the chambers. On Days 3 and 4, rats were injected with either saline (Group Saline) or naloxone (Group Naloxone) and placed into the chambers. One of the CSs, A, was presented 20 times. On Day 5, all rats were conditioned drug-free to the pre-exposed CSA and to a

Table I Design of Experiments la and Ib

\begin{tabular}{lllll}
\hline Experiment & Group & Pre (drug) & Cond & Test (drug) \\
\hline Experiment la & Saline & $\mathrm{A}-(\mathrm{Sal})$ & $\mathrm{A}+, \mathrm{B}+$ & $\mathrm{A}-, \mathrm{B}-$ \\
& Naloxone & $\mathrm{A}-(\mathrm{Nal})$ & $\mathrm{A}+, \mathrm{B}+$ & $\mathrm{A}-, \mathrm{B}-$ \\
& & & & \\
Experiment Ib & Saline & $\mathrm{A}-(\mathrm{Sal})$ & $\mathrm{A}+, \mathrm{B}+$ & $\mathrm{A}-, \mathrm{B}-(\mathrm{Nal})$ \\
& Naloxone & $\mathrm{A}-(\mathrm{Nal})$ & $\mathrm{A}+, \mathrm{B}+$ & $\mathrm{A}-, \mathrm{B}-(\mathrm{Nal})$ \\
\hline
\end{tabular}

Note: $\mathrm{A}$ and $\mathrm{B}$ are tone and flashing light (counterbalanced). $+=$ shock; - = no shock; Sal = saline; $\mathrm{Nal}=$ naloxone; Pre = pre-exposure;

Cond $=$ conditioning. Pre-exposures to $\mathrm{A}$ were given in two sessions over 2 days. All other stages were given in a single session per day. All injections were made 5 min before behavioral procedures. 
novel CSB. Each CS received a single pairing with a shock US, which coterminated with each CS presentation in counterbalanced order separated by a 3-min interval. On Day 6, rats were tested for freezing to both CSA and CSB drug-free (Experiment 1a) or under naloxone (Experiment 1b). Each was presented four times with a 2-min intertrial interval.

\section{Experiment 2: Effect of Passage of Time Between Exposures on Latent Inhibition and its Blockade by Naloxone}

Design. A $3 \times 2$ design was used to examine whether latent inhibition is enhanced when a passage of time is interpolated between initial exposure and re-exposure to a stimulus (A) relative to a stimulus (B) given equivalent but successive exposures, and whether any such enhancement occurring to A (relative to B) at the time of re-exposure is mediated by opioids; thus, susceptible to disruption by naloxone. Rats were first pre-exposed to one stimulus (A) and then to another (B) some time later. Shortly after pre-exposure to $\mathrm{B}$, additional exposures were given to both the remotely exposed A and the recently exposed $B$ under either saline (Saline Groups) or naloxone (Naloxone Groups). To avoid generalization between stimuli of similar reinforcement history, rats were then conditioned and tested to either CSA (Remote Groups) or CSB (Recent Groups). To document a basic latent inhibition effect, two additional controls were included: rats were treated identically and injected with saline (Saline-Control) or naloxone (Naloxone-Control) but were not given any CS pre-exposures (Table 2).

Procedure. Rats were allocated to six groups: SalineControl ( $n=7$; one was culled before the experiment because of ill health), Saline-Recent $(n=8)$, Saline-Remote $(n=8)$, Naloxone-Control $(n=8)$, Naloxone-Recent $(n=8)$, and Naloxone-Remote $(n=8)$. All rats were exposed to the chambers on Days 1 and 2 in the manner described. On Day 3 , all rats were injected with saline and placed into the chambers. All Recent and Remote Groups were exposed to one of the CSs, A, over 20 presentations; Control Groups received equivalent exposures to the chambers. All rats remained in the colony room over the next 9 days. On Day 13, all rats were again injected with saline and returned to the chambers. All Recent and Remote Groups were exposed to the other CS, B, over 20 presentations; Control Groups received equivalent exposures to the chambers. Five minutes after this exposure, all Saline Groups were given an injection of saline and all Naloxone Groups were injected with naloxone. All Recent and Remote Groups were then exposed to both $\mathrm{A}$ and $\mathrm{B}$ over 10 trials; Control Groups received equivalent exposures to the chambers. On Day 14, Groups Saline-Remote and Naloxone-Remote received a single pairing of A with the US; Groups Saline-Recent and Naloxone-Recent received a single pairing of B with the US; Groups Saline-Control and Naloxone-Control were conditioned in the same way to a novel CS physically identical to those used for A and B in the other groups. On Day 15, all rats were tested over four trials to the CS conditioned on the previous day.

\section{Experiment 3: Effect of Compound Novel Stimulus During Re-Exposure on Latent Inhibition and its Blockade by Naloxone}

Design. A $3 \times 2$ design was again used to examine whether latent inhibition to an already pre-exposed stimulus (A) is enhanced when additional exposures are given in compound with a novel stimulus (AX) relative to one pre-exposed in isolation (B), and whether any such enhancement to A (relative to B) occurring at re-exposure is opioid-mediated, and therefore susceptible to disruption by naloxone (Saline $v s$ Naloxone Groups). Again, rats were conditioned and tested to either CSA (Compound Groups) or CSB (Element Groups). Two control groups were treated identically and injected with saline (Saline-Control) or naloxone (Naloxone-Control) but were not given any CS pre-exposures (Table 3).

Procedure. Rats were allocated randomly to six groups: Saline-Control $(n=4)$, Saline-Element $(n=8)$, Saline-Compound $(n=8)$, Naloxone-Control $(n=4)$, Naloxone-Element $(n=8)$, and Naloxone-Compound $(n=8)$. Four CS were used and were counterbalanced in the manner described previously (Leung et al, 2011; Experiment 5). All animals were exposed to the chambers on Days 1 and 2. On Day 3, all rats were injected with saline and placed into the chambers. All Element and Compound Groups were given 10 presentations of $\mathrm{A}$ and 10 of $\mathrm{B}$; Control Groups received equivalent exposures to the chambers. On Day 4, rats were injected with either saline (Saline Groups) or naloxone (Naloxone Groups) and returned to the chambers. All Element and Compound Groups were given a single presentation of $A$ and of $B$,

Table 2 Design of Experiment 2

\begin{tabular}{|c|c|c|c|c|c|c|}
\hline Group & Pre & Retention & Pre & Pre (drug) & Cond & Test \\
\hline Saline-Control & - & & - & $-(\mathrm{Sal})$ & $\mathrm{A}+$ or $\mathrm{B}+$ & $A-$ or $B-$ \\
\hline Saline-Recent & $A-$ & & $B-$ & $A-, B-(S a l)$ & $\mathrm{B}+$ & $B-$ \\
\hline Saline-Remote & $A-$ & & $B-$ & $A-, B-(S a l)$ & $\mathrm{A}+$ & $A-$ \\
\hline Naloxone-Control & - & & - & $-(\mathrm{Nal})$ & $\mathrm{A}+$ or $\mathrm{B}+$ & $A-$ or $B-$ \\
\hline Naloxone-Recent & $A-$ & & $B-$ & $\mathrm{A}-, \mathrm{B}-(\mathrm{Nal})$ & $\mathrm{B}+$ & $B-$ \\
\hline
\end{tabular}

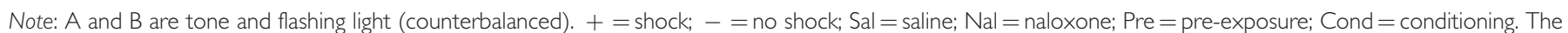
retention interval was 9 days. 
Table 3 Design of Experiment 3

\begin{tabular}{lllll}
\hline Group & Pre & Pre (drug) & Cond & Test \\
\hline Saline-Control & - & $-(\mathrm{Sal})$ & $\mathrm{A}+$ or $\mathrm{B}+$ & $\mathrm{A}-$ or B - \\
Saline-Element & $\mathrm{A}-, \mathrm{B}-$ & $\mathrm{A} X-, \mathrm{B}-(\mathrm{Sal})$ & $\mathrm{B}+$ & $\mathrm{B}-$ \\
Saline-Compound & $\mathrm{A}-, \mathrm{B}-$ & $\mathrm{A} X-, \mathrm{B}-(\mathrm{Sal})$ & $\mathrm{A}+$ & $\mathrm{A}-$ \\
Naloxone-Control & - & $-(\mathrm{Nal})$ & $\mathrm{A}+$ or $\mathrm{B}+$ & $\mathrm{A}-$ or B- \\
Naloxone-Element & $\mathrm{A}-, \mathrm{B}-$ & $\mathrm{A}-, \mathrm{B}-(\mathrm{Nal})$ & $\mathrm{B}+$ & $\mathrm{B}-$ \\
Naloxone-Compound & $\mathrm{A}-, \mathrm{B}-$ & $\mathrm{A} X-, \mathrm{B}-(\mathrm{Nal})$ & $\mathrm{A}+$ & $\mathrm{A}-$ \\
\hline
\end{tabular}

Note: $A, B$, and $X$ are tone, clicker, steady light, or flashing light counterbalanced with the constraint that $A$ and $B$ are drawn from one modality and $X$ from another. $+=$ shock; $-=$ no shock; Sal = saline; $\mathrm{Nal}=$ naloxone;

Pre $=$ pre-exposure; Cond $=$ conditioning.

followed by 10 presentations of a stimulus compound composed of a pre-exposed A and a novel stimulus X (AX) and 10 presentations of $\mathrm{B}$ in isolation; Control Groups received equivalent exposures to the chambers. On Day 5, Groups Saline-Element and Naloxone-Element received a single pairing of CSB and the US; Groups Saline-Compound and Naloxone-Compound received a pairing of CSA and the US; Groups Saline-Control and Naloxone-Control were conditioned to a novel CS physically identical to A and B. On Day 6, all rats tested across four presentations of the CS conditioned on the previous day.

Data analysis. Freezing responses during the CS and the 30 -s pre-CS period were scored every $2 \mathrm{~s}$ by two observers, one of whom was blind to the experimental treatment of each subject. Correlation between their scoring was high, $r>0.9$. Any discrepancies were resolved in favor of the naive observer. Freezing was defined as the absence of all movements except those related to breathing. The number of occasions on which freezing was observed was expressed as a percentage of the total number of observations. The data were analyzed with planned contrasts in a multivariate model of ANOVA. The Type I error rate was controlled at $\alpha=0.05$. No differences in pre-CS responding exceeded statistical significance in any of the experiments.

\section{RESULTS}

\section{Experiments 1a and 1b: Naloxone Impairs the Latent Inhibitory Effect of Pre-exposure}

Figure 1 shows the mean levels of freezing to each CS on test in Experiment 1a. Rats pre-exposed under saline froze significantly less to the pre-exposed CSA than to the control $\mathrm{CSB}, \mathrm{F}_{(1,14)}=41.8, \mathrm{~F}_{\text {critical }}=4.6$, showing that pre-exposure had latently inhibited CSA. In contrast, rats pre-exposed under naloxone froze just as much to the pre-exposed CSA as the control $\mathrm{CSB}, \mathrm{F}<1$, indicating that naloxone had prevented the latent inhibitory effect of pre-exposure. Moreover, rats pre-exposed under naloxone froze significantly more to the pre-exposed CSA than rats pre-exposed under saline, $F_{(1,14)}=14.8$, confirming that naloxone had impaired the latent inhibitory effect of pre-exposure. This impairment was specific to the pre-exposed CSA, as there was no significant difference between the levels of freezing to the control CSB among rats pre-exposed under naloxone or saline, $\mathrm{F}<1$.

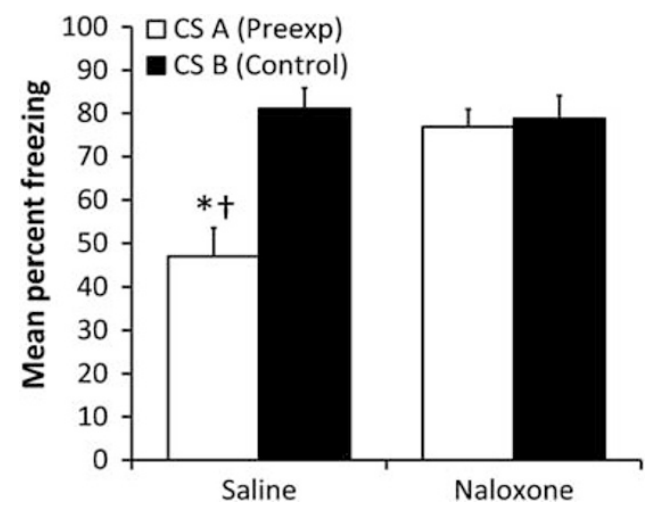

Figure I Result of Experiment la. Effect of systemic naloxone administration during conditioned stimulus (CS) pre-exposure on latent inhibition in a drug-free test. Rats were pre-exposed to one CS (A) under saline (Group Saline) or naloxone (Group Naloxone) and conditioned and tested drug-free to the pre-exposed CSA and to a control novel CSB. *A Significant effect of pre-exposure; ‘a significant effect of drug.

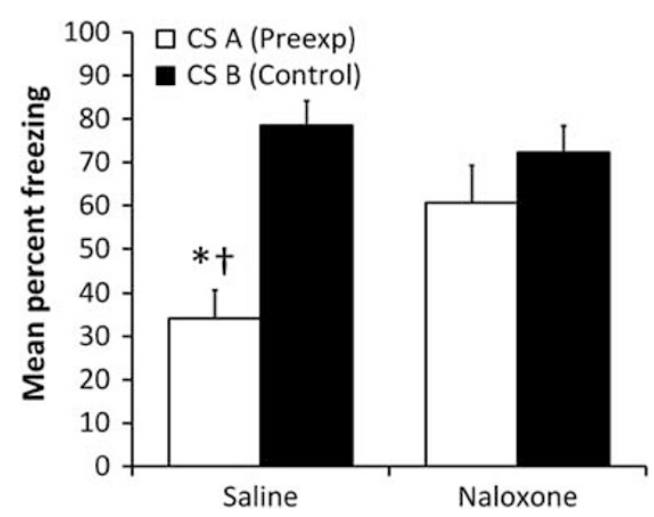

Figure 2 Result of Experiment lb. Effect of systemic naloxone administration during conditioned stimulus (CS) pre-exposure on latent inhibition in a naloxone test. Rats were pre-exposed to one CS (A) under saline (Group Saline) or naloxone (Group Naloxone), conditioned drugfree, and tested under naloxone to the pre-exposed CSA and to a control novel CSB. *A significant effect of pre-exposure; ${ }^{\dagger}$ a significant effect of drug.

It is possible that rats in Group Naloxone learned that the stimulus signaled nothing across pre-exposure but encoded this learning against the background of drug-related cues, and the absence of these cues at test led to a retrieval failure of that learning. To address this issue, Experiment $1 \mathrm{~b}$ repeated the procedures of Experiment 1a, except that subjects were tested under naloxone rather than in a drugfree state. This did not alter the outcome of the experiment. As shown in Figure 2, Group Saline froze less to the preexposed $\mathrm{A}$ than to the control $\mathrm{B}, \mathrm{F}_{(1,14)}=39.7, \mathrm{~F}_{\text {critical }}=4.6$. In Group Naloxone, the difference in freezing responses to the pre-exposed $\mathrm{A}$ and the non-pre-exposed $\mathrm{B}$ was not significant, $F_{(1,14)}=2.7$. As in the previous experiment, rats in Group Naloxone also froze significantly more to the preexposed A than Group Saline, $\mathrm{F}_{(1,14)}=6.0$, but did not differ in their levels of freezing from those in Group Saline to the control $\mathrm{B}, \mathrm{F}<1$. Taken together, these experiments suggest that the failure to detect a latent inhibitory effect among rats pre-exposed under naloxone is not due to state-dependent learning. 
Experiment 2: Naloxone Prevents the Enhancement of Latent Inhibition by a Passage of Time Between Exposures

The results are shown in Figure 3. Among the saline-treated rats, there was a latent inhibition effect to both $\mathrm{A}$ and $\mathrm{B}$, $\mathrm{F}_{(1,41)}=54.3, \mathrm{~F}_{\text {critical }}=4.1$, as rats conditioned to the novel CS (Group Saline-Control) responded more than rats preexposed to A (Group Saline-Recent) and to B (Group Saline-Recent). Moreover, a long retention interval interpolated between the initial and second exposure to A allowed it to acquire greater latent inhibition than $\mathrm{B}$, as rats conditioned with the pre-exposed B (Group Saline-Recent) responded more than rats conditioned with the pre-exposed A (Group Saline-Remote), $F_{(1,41)}=30.2$. Among the naloxone-treated rats, there was also a latent inhibition effect to both $A$ and $B$, as rats conditioned to the novel CS (Group Naloxone-Control) responded more than rats pre-exposed to A (Group Naloxone-Remote) and to B (Group Naloxone-Recent), $F_{(1,41)}=12.9$. However, there was no evidence that latent inhibition to $\mathrm{A}$ was enhanced relative to $\mathrm{B}, \mathrm{F}<1$. Comparisons between the naloxone- and saline-treated rats showed that naloxone significantly impaired the enhanced latent inhibition effect to A (Groups Saline-Remote $v s$ Naloxone-Remote), $\left.\quad \mathrm{F}_{(1,}, 41\right)=29.8$, but was without effect on B (Groups Saline-Recent $v s$ Naloxone-Recent) or a novel CS (Groups Saline-Control vs Naloxone-Control), Fs $\leqslant 1.4$. These results show that an administration of naloxone during a common re-exposure session to both the remotely exposed A and the recently exposed B selectively blocked the enhancement of latent inhibition to $\mathrm{A}$ while leaving the basic latent inhibition effect already accrued to B intact.

Experiment 3: Naloxone Prevents the Enhancement of Latent Inhibition by Compound Presentations with a Novel Stimulus

As shown in Figure 4, there was again a basic latent inhibition effect among the saline-treated rats, $F_{(1,34)}=$ $19.7, \mathrm{~F}_{\text {critical }}=4.1$, and the naloxone-treated rats, $\mathrm{F}_{(1,34)}=$ 20.2. Among rats injected with saline, latent inhibition was enhanced to $A$ relative to $B, F_{(1,34)}=9.9$. However, this effect was absent among those injected with naloxone, $\mathrm{F}<1$. This is because naloxone impaired the enhanced latent inhibition effect in $A, F_{(1,34)}=5.7$, but was without effect on $\mathrm{B}$ or a novel CS, Fs $<1$. Thus, naloxone again blocked the enhancement of latent inhibition by compounding an already pre-exposed target with a novel stimulus.

\section{DISCUSSION}

As far as we are aware, these experiments have provided the first systematic investigation of the role of endogenous opioids in the latent inhibition of Pavlovian fear conditioning. The results are consistent with the role of opioids in regulating the discrepancy or prediction error between what is expected and what actually occurs in fear conditioning. For instance, it has been shown that naloxone enhances acquisition of conditioned freezing or hypoalgesic responses to CSs predicting a painful US (eg, Foo and Westbrook, 1991; Young and Fanselow, 1992). These

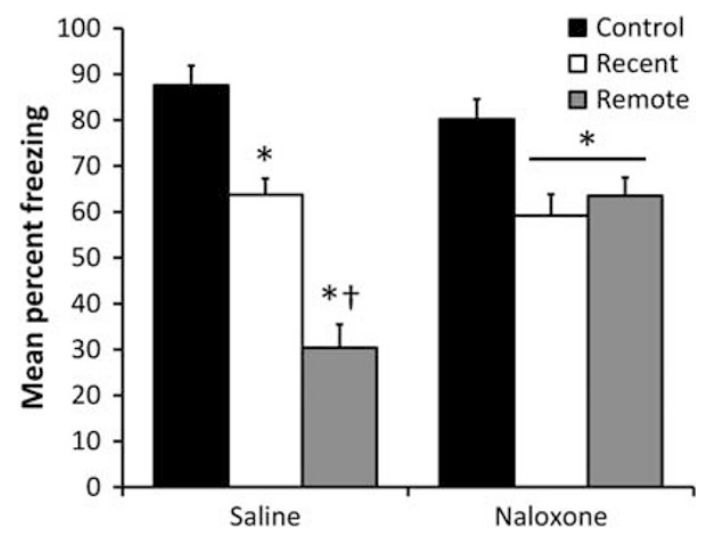

Figure 3 Result of Experiment 2. Effect of systemic naloxone administration on latent inhibition during a common re-exposure session to a recently pre-exposed conditioned stimulus (CS) (B; Groups SalineRecent and Naloxone-Recent) or to a remotely pre-exposed CS (A; Groups Saline-Remote and Naloxone-Remote) or to the context alone (Groups Saline-Control and Naloxone-Control). *A significant effect of pre-exposure; 'a significant effect of drug.

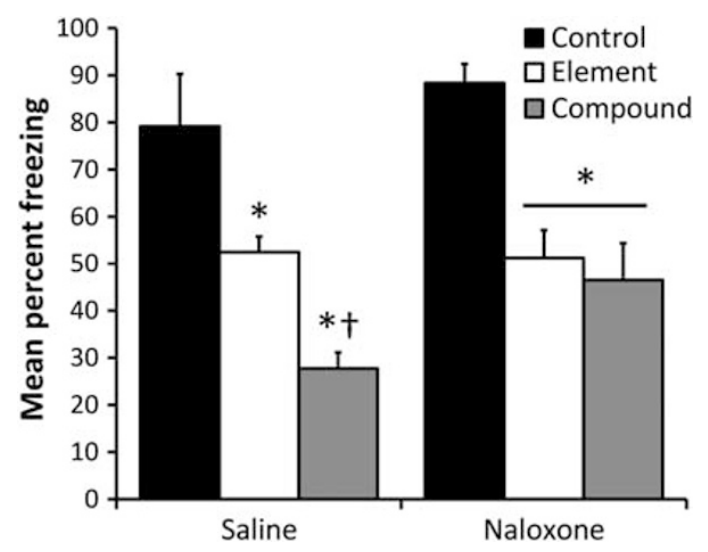

Figure 4 Result of Experiment 3. Effect of systemic naloxone administration on latent inhibition during a common re-exposure session to a pre-exposed conditioned stimulus (CS) (B; Groups Saline-Element and Naloxone-Element) or to stimulus compound $(A X)$ composed of a preexposed CS (A) and a novel stimulus ( $X$; Groups Saline-Compound and Naloxone-Compound) or to the context alone (Groups Saline-Control and Naloxone-Control). *A significant effect of pre-exposure; ' ${ }^{\dagger}$ significant effect of drug.

facilitatory effects of naloxone on fear acquisition raised the possibility that endogenous opioids instantiate an error-correction mechanism for fear conditioning through its role in antinociception (Fanselow, 1998). Specifically, when a CS signals the occurrence of an aversive US, typically a footshock, the CS will come to evoke an opioidmediated analgesic response, which acts to reduce the perceived intensity of the shock US. This conditioned analgesic response is blocked by naloxone, maintaining the perceived intensity of the shock US, thereby enhancing fear conditioning. However, the role of opioids in error correction is not limited to learning about painful stimuli. For instance, naloxone enhances second-order conditioning when an established fear CS is used in place of the aversive reinforcer (Cicala et al, 1990). Critically, naloxone impairs fear extinction when an expected US is absent (McNally and 
Westbrook, 2003). The opposite effects of naloxone on fear acquisition and fear extinction suggests that endogenous opioids do not simply enhance or impair associative learning; rather, they perform a computational function in fear conditioning, specifically encoding the subtractive component $\left(-\sum V\right)$ in the error term $\left(\lambda-\sum V\right)$ described by error-correction models (McNally et al, 2004, 2011; McNally, 2009). When prediction error is positive, blockade of this subtractive component augments the positive error signal and facilitates fear conditioning. When prediction error is negative, its blockade diminishes the negative error signal and impairs fear extinction.

The present result that naloxone also impairs latent inhibition suggests that latent inhibition, like extinction, is regulated by negative prediction error, and that the resulting formation of an inhibitory or stimulus-no event association leads to a decline in the attention or the learning rate parameter $(\alpha)$ associated with the CS (Hall and Rodriguez, 2010; Leung et al, 2011, 2013). There is evidence that a novel or surprising stimulus can evoke unconditioned responses through the release of endogenous opioids, including analgesia, and that the reduction in these responses across exposures to the stimulus is blocked by naloxone (eg, Cador et al, 2002; Foo and Westbrook, 1991; Hernandez and Watson, 1997; Izquierdo et al, 1984; Rochford and Dawes, 1993). Accordingly, naloxone disrupted the error signal, which normally drives the formation of the inhibitory association in latent inhibition. The absence of this inhibitory association maintains the ability of the stimulus to elicit an event expectation, and hence the attention paid to that stimulus. When such stimulus enters conditioning, it should condition just as rapidly as a novel stimulus (Experiments $1 \mathrm{a}$ and $1 \mathrm{~b}$ ). Further, if prediction error provides the computational substrate for naloxone to exert its effect, then an already pre-exposed stimulus which fails to generate prediction error will be insensitive to the effects of naloxone across additional exposures. In Experiments 2 and 3, rats first pre-exposed to a stimulus (B) drug-free and then given additional exposures to that stimulus under naloxone did not show any impairment in latent inhibition. Thus, naloxone does not reverse the latent inhibition already accrued to a stimulus. In contrast, a pre-exposed stimulus (A) given additional exposures when prediction error has been restored either by a lapse of time since initial exposure (Experiment 2) or by an added novel stimulus (Experiment 3) undergoes an enhancement of latent inhibition, thus providing the condition which rendered the stimulus again sensitive to naloxone. Taken together, these results suggest that attentional loss in latent inhibition is driven by an opioid-mediated error signal which diminishes with repeated stimulus exposures but recovers with the passage of time or reintroduction of novelty.

The present demonstrations used a fear conditioning procedure to assess the role of endogenous opioids in latent inhibition. It remains to be determined whether these results would also be observed in appetitive conditioning procedures. Available evidence in other behavioral paradigms suggests that opioids may have a more general function in directing attention towards stimuli of potential motivational significance. For example, it has been shown that enhancement or blockade of opioid neurotransmission in the ventral tegmental area respectively enhances and impairs locomotor responses in a novel environment but not in a familiar one (eg, Cador et al, 2002). In the case of central amygdala, opioid activation has also been shown to potentiate appetitive responses evoked by reward or reward-signaling stimuli (eg, Mahler and Berridge, 2009). However, it remains to be determined to what extent the decrement of these responses in latent inhibition or extinction similarly requires opioid activation. It is also worth noting that these results are consistent with the suggestion that the inability to ignore irrelevant stimuli, which characterizes positive symptoms in schizophrenia, may originate from dysfunctions in error-correction learning (eg, Corlett et al, 2007; Morris et al, 2012). The sensitivity of this learning to naloxone implicates endogenous opioids as a potential pharmacological target for the treatment of schizophrenia, and is consistent with post-mortem analysis showing alterations in cortical opioid receptors in the brains of schizophrenics (Volk et al, 2012). The exact site of action, relative contribution of each receptor subtypes, and their interaction with other neurotransmitters, such as dopamine, remain to be determined in future research.

\section{FUNDING AND DISCLOSURE}

The authors declare no conflict of interest.

\section{ACKNOWLEDGEMENTS}

This study is supported by a grant from Australian Research Council to RFW and ASK (DP1096570). We thank Gavan McNally for comments.

\section{REFERENCES}

Baruch I, Hemsley DR, Gray JA (1988). Differential performance of acute and chronic schizophrenics in a latent inhibition task. J Nerv Ment Dis 176: 598-606.

Cador M, Marco N, Stinus L, Simonnet G (2002). Interaction between neuropeptide FF and opioids in the ventral tegmental area in the behavioral response to novelty. Neuroscience 110: 309-318.

Cicala GA, Azorlosa JL, Estall LB, Grant SJ (1990). Endogenous opioids interfere with Pavlovian second-order fear conditioning. Psychol Sci 1: 312-315.

Corlett PR, Murray GK, Honey GD, Aitken MR, Shanks DR, Robbins TW et al (2007). Disrupted prediction-error signal in psychosis: evidence for an associative account of delusions. Brain 130: 2387-2400.

Fanselow MS (1998). Pavlovian conditioning, negative feedback, and blocking: mechanisms that regulate association formation. Neuron 20: 625-627.

Foo H, Westbrook RF (1991). Naloxone-induced hypoalgesia: effects of heat, cold and novelty. Q J Exp Psychol B 43: 137-156.

Gray NS, Pilowsky LS, Gray JA, Kerwin RW (1995). Latent inhibition in drug naive schizophrenics: relationship to duration of illness and dopamine D2 binding using SPET. Schizophr Res 17: 95-107.

Hall G, Rodriguez G (2010). Associative and nonassociative processes in latent inhibition: an elaboration of the PearceHall model. In: Lubow REWeiner IN (eds) Latent Inhibition: 
Data, Theories, and Applications to Schizophrenia. Cambridge University Press: Cambridge, UK, pp 114-136.

Hernandez LL, Watson KL (1997). Opioid modulation of attentionrelated responses: delta-receptors modulate habituation and conditioned bradycardia. Psychopharmacology 131: 140-147.

Holtzman O, Siette J, Holmes NM, Westbrook RF (2010). Additional exposures reverse the latent inhibitory effects of recent and remote exposures. J Exp Psychol Anim Behav Process 36: 368-380.

Izquierdo I, Souza DO, Dias RD, Perry ML, Carrasco MA, Volkmer $\mathrm{N}$ et al (1984). Effect of various behavioral training and testing procedures on brain beta-endorphin-like immunoreactivity and the possible role of beta-endorphin in behavioral regulation. Psychoneuroendocrinology 9: 381-389.

Leung HT, Killcross AS, Westbrook RF (2011). Additional exposures to a compound of two preexposed stimuli deepen latent inhibition. J Exp Psychol Anim Behav Process 37: 394-406.

Leung HT, Killcross AS, Westbrook RF (2013). A further assessment of the Hall-Rodriguez theory of latent inhibition. J Exp Psychol Anim Behav Process 39: 117-125.

Leung HT, Westbrook RF (2008). Spontaneous recovery of extinguished fear responses deepens their extinction: a role for error-correction mechanisms. J Exp Psychol Anim Behav Process 34: 461-474.

Lubow RE, Moore AU (1959). Latent inhibition: the effect of nonreinforced pre-exposure to the conditional stimulus. J Comp Physiol Psychol 52: 415-419.

Lubow RE, Weiner I, Schnur P (1981). Conditioned attention theory. In: Bower GH (eds) The Psychology of Learning and Motivation. Academic Press: San Diego, CA, USA, pp 1-49.

Mackintosh NJ (1975). A theory of attention: variations in the associability of stimuli with reinforcement. Psychol Rev 82: 276-298.

Mahler SV, Berridge KC (2009). Which cue to 'want?' Central amygdala opioid activation and focuses incentive salience on a prepotent reward cue. J Neurosci 29: 6500-6513.
McNally GP (2009). The role of endogenous opioids in fear learning. Int J Comp Psychol 22: 154-170.

McNally GP, Johansen JP, Blair HT (2011). Placing prediction into the fear circuit. Trends Neurosci 34: 283-292.

McNally GP, Pigg M, Weidemann G (2004). Blocking, unblocking, and overexpectation of fear: opioid receptors regulate Pavlovian association formation. Behav Neurosci 117: 1292-1301.

McNally GP, Westbrook RF (2003). Opioid receptors regulate the extinction of Pavlovian fear conditioning. Behav Neurosci 117: $1292-1301$.

Morris RW, Vercammen A, Lenroot R, Moore L, Langton JM, Short B et al (2012). Disambiguating ventral striatum fMRI-related BOLD signal during reward prediction in schizophrenia. Mol Psychiatry 17: 280-289.

Pearce JM, Hall G (1980). A model for Pavlovian learning: variations in the effectiveness of conditioned but not of unconditioned stimuli. Psychol Rev 87: 532-552.

Reiss S, Wagner AR (1972). CS habituation produces a 'latent inhibition effect' but no active 'conditioned inhibition'. Learn Motiv 30: 35-52.

Rochford J, Dawes P (1993). Effect of naloxone on the habituation of novelty-induced hypoalgesia: the collateral inhibition hypothesis revisited. Pharmacol Biochem Behav 46: 117-123.

Vaitl D, Lipp O, Bauer U, Schuler G, Stark R, Zimmermann M et al (2002). Latent inhibition and schizophrenia: Pavlovian conditioning of autonomic responses. Schizophr Res 55: 147-158.

Volk DW, Radchenkova PV, Walker EM, Sengupta EJ, Lewis DA (2012). Cortical opioid markers in schizophrenia and across postnatal development. Cereb Cortex 22: 1215-1223.

Young SL, Fanselow MS (1992). Associative regulation of Pavlovian fear conditioning: unconditional stimulus intensity, incentive shifts, and latent inhibition. J Exp Psychol Anim Behav Process 18: 400-413. 